\title{
The score of integrated disease surveillance and response adequacy (SIA): a pragmatic score for comparing weekly reported diseases based on a systematic review
}

Bien-Aimé Makasa Mandja ${ }^{1,2^{*}}$ (D), Didier Bompangue ${ }^{1,2}$, Pascal Handschumacher ${ }^{3}$, Jean-Paul Gonzalez ${ }^{4}$, Gérard Salem ${ }^{5}$, Jean-Jacques Muyembe ${ }^{1,6}$ and Frédéric Mauny ${ }^{2,7}$

\begin{abstract}
Background: The Integrated Disease Surveillance and Response (IDSR) strategy implemented by the World Health Organization (WHO) in Africa has produced a large amount of data on participating countries, and in particular on the Democratic Republic of Congo (DRC). These data are increasingly considered as unevaluable and, therefore, as requiring a rigorous process of validation before they can be used for research or public health purposes. The aim of this study was to propose a method to assess the level of adequacy of IDSR morbidity data in reflecting actual morbidity.
\end{abstract}

Methods: A systematic search of English- and French-language articles was performed in Scopus, Medline, Science Direct, Springer Link, Cochrane, Cairn, Persée, and Erudit databases. Other types of documents were identified through manual searches. Selected articles focused on the determinants of the discrepancies (differences) between reported morbidity and actual morbidity. An adequacy score was constructed using some of the identified determinants. This score was applied to the 15 weekly reported diseases monitored by IDSR surveillance in the DRC. A classification was established using the Jenks method and a sensitivity analysis was performed. Twenty-three classes of determinants were identified in 35 IDSR technical guides and reports of outbreak investigations and in 71 out of 2254 researched articles. For each of the 15 weekly reported diseases, the SIA was composed of 12 items grouped in 6 dimensions.

Results: The SIA classified the 15 weekly reported diseases into 3 categories or types: high score or good adequacy (value $>=14$ ), moderate score or fair adequacy (value $>=8$ and $<14$ ), and low score or low or non-adequacy (value $<8$ ). Regardless of the criteria used in the sensitivity analysis, there was no notable variation in SIA values or categories for any of the 15 weekly reported diseases.

Conclusion: In a context of sparse health information in low- and middle-income countries, this study developed a score to help classify IDSR morbidity data as usable, usable after adjustment, or unusable. This score can serve to prioritize, optimize, and interpret data analyses for epidemiological research or public health purposes.

Keywords: Adequacy score, Democratic Republic of Congo, Infectious diseases, Integrated disease surveillance and response, Reported data

\footnotetext{
* Correspondence: mmandja@gmail.com

'Service de Microbiologie, Faculté de Médecine, Université de Kinshasa,

Kinshasa, Democratic Republic of Congo

²Laboratoire Chrono-Environnement, UMR 6249 CNRS, Université de

Bourgogne Franche-Comté, Besançon, France

Full list of author information is available at the end of the article
}

(c) The Author(s). 2019 Open Access This article is distributed under the terms of the Creative Commons Attribution 4.0 International License (http://creativecommons.org/licenses/by/4.0/), which permits unrestricted use, distribution, and reproduction in any medium, provided you give appropriate credit to the original author(s) and the source, provide a link to the Creative Commons license, and indicate if changes were made. The Creative Commons Public Domain Dedication waiver (http://creativecommons.org/publicdomain/zero/1.0/) applies to the data made available in this article, unless otherwise stated. 


\section{Introduction}

Sub-Saharan Africa has the highest total morbidity and mortality burden of infectious diseases in the world [1]. In 2012, global morbidity in the region was estimated at 74,000 per 100,000 inhabitants. This number is nearly twice that of the Eastern Mediterranean or South-East Asian regions (40,779 and 40,341 per 100,000 inhabitants, respectively) [2]. In addition, approximately half the mortality from all types of infectious diseases in the world occurs in Sub-Saharan Africa [3, 4]. While emerging non-transmittable diseases have expanded in the region in the last two decades, infectious diseases remain a major public health concern [3, 4]. By the end of the 1990s, most sub-Saharan African countries had seen major public health events or outbreaks. Huge epidemics occurred in the DRC, including the large cholera outbreak in the Rwandan Hutu refugee camp in Goma in 1994 [5], the 1000 cases of poliomyelitis reported in Mbuji-Mayi in 1995 [6, 7], and the largest ever monkey pox outbreak that took place in Sankuru in 1996-1997 [8]. Overall, the growing epidemic risk in sub-Saharan African countries is a source of major international concern.

In 1998, an Integrated Disease Surveillance and Response (IDSR) strategy was initiated under the guidance of the WHO Regional Office for Africa (WHO AFRO) to prevent and control these multiple epidemic emergencies $[9,10]$. This strategy works by reinforcing national public health surveillance and response systems in the region. According to the IDSR technical guidelines, the specific objectives of the strategy are to: 1) integrate vertical disease surveillance systems for effective and efficient use of resources; 2) improve the flow and use of information for detecting and responding to public health threats; and 3) improve country capacity to detect and respond to priority public health events [10, 11]. The IDSR strategy, which relies on systematic and continuous data collection and reporting by health care facilities, has eight functions: identification, notification, analysis and interpretation, epidemic investigation and confirmation, preparation, response, circulation of information and evaluation, and improvement of the system [11-14]. Depending on the health specificity of each country, WHO AFRO recommends IDSR surveillance of a number of priority transmittable diseases (weekly reporting) and non-transmittable diseases (monthly reporting) [11]. This timely continuous epidemiological surveillance improves the availability and use of data on the leading causes of illness, death, and disability in the region [15]. As such, the IDSR strategy contributes to high-level decision-making in the area of public health in participating countries.

In addition to contributing to disease outbreak prevention and control, IDSR morbidity data are increasingly relevant to epidemiological research. In particular, they are now being used to determine the spatial and temporal dynamics of various diseases [16-18]. They thus constitute an alternative to other techniques for generating health data in low and middle-income countries (e.g., demographic health surveys, STEPS surveys, household surveys, etc.). While these techniques can produce reliable data, they are indeed very costly to implement [19]. In the DRC, more and more epidemiological studies rely on the large amount of data that have been produced since the 1999 implementation of the IDSR strategy.

It has been demonstrated, however, that the IDSR strategy results in social and spatial discrepancies (differences) in disease distribution between reported cases (reported morbidity) and field reality (actual morbidity). In the particular context of the DRC, this is likely because IDSR morbidity data reporting is based on a syndromic approach [19-22]. Unfortunately, these discrepancies cast doubt on the validity of epidemiological studies using IDSR morbidity data. Because the true value and accuracy of these data are difficult to evaluate $[19,20,22]$, there is a pressing need to develop a method for validating them before they can be used for research or public health purposes.

While some approaches have been proposed to assess the quality of IDSR morbidity data, they focus on a limited number of diseases. These approaches include: 1) a method for assessing the "relevance and validity" of IDSR morbidity data on chickenpox, hepatoma, anaemia, malnutrition, and measles [20]; 2) a method for constructing, comparing and spatializing selected indicators and indices for analyses of malaria based on IDSR morbidity data [19]; or 3) a method using a tree model scenario to estimate the proportion of lost cases of monkey pox in the DRC health system due to IDSR data reporting [23]. To our knowledge, no method applicable to all diseases monitored by IDSR surveillance and assessing the discrepancies between "reported morbidity" and "actual morbidity" has been published.

The aim of this article is to propose a method for assessing the level of adequacy of IDSR morbidity data in reflecting the actual morbidity of the 15 weekly reported diseases monitored by IDSR surveillance in the DRC.

\section{Methods}

\section{Study setting}

Located in Central Africa, the DRC had a total area of 2.3 million $\mathrm{km}^{2}$ and an estimated population of $86,895,208$ inhabitants in 2016 [24]. In 2015, the country was subdivided into 26 administrative provinces (Fig. 1). The health system in the DRC is a three-tier (central, intermediate, and peripheral) pyramidal structure. The 

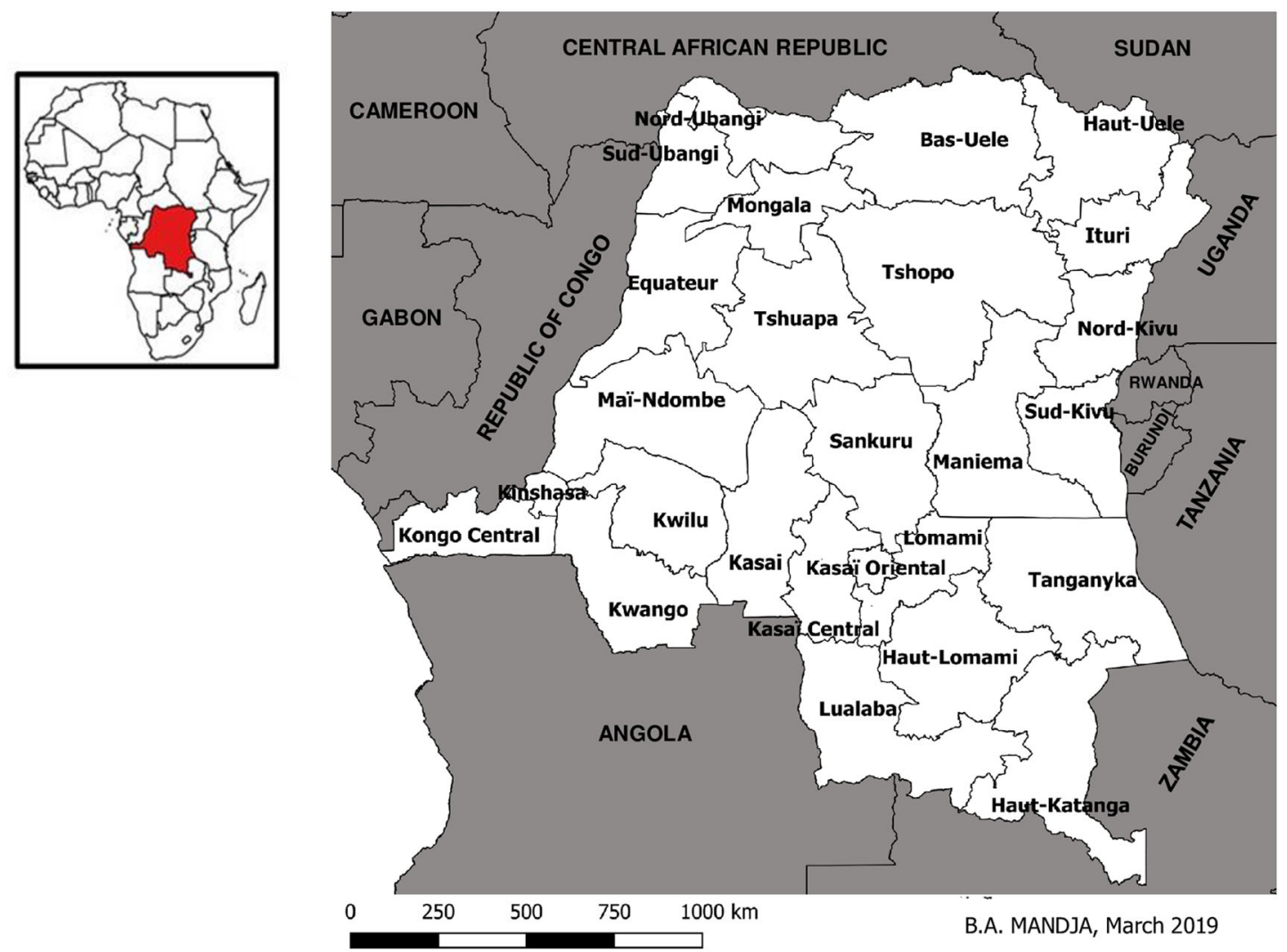

Fig. 1 Administrative map of the DRC including 26 new provinces and bordering countries, (Source: The map was created with the provincial Shapefile obtained from the free, open, collaborative platform Common geographical reference of DRC (https://data.humdata.org/dataset/drcongo-settlements). The map was created using the free software QGIS 12.8 geographical information system)

central level sets standards and is composed of the Minister's office and the general secretariat, which includes 13 directorates and 52 specialized programs. The intermediate level has a technical and logistical role and is composed of 26 provincial health divisions and provincial hospitals. The peripheral level has an operational role in the implementation of primary health care. This level consists of 515 Health Zones (HZ), which include 393 General Reference Hospitals (GRH) and 8504 planned Health Areas (HA), 8266 of which have a Health Center (HC) [25].

\section{Organization of the surveillance system in the DRC}

In the DRC, the IDSR strategy is managed by the General Direction of Disease Control (GDDC). Since 2000, the DRC has been monitoring 12 weekly reported diseases with acute epidemic potential, namely: acute flaccid paralysis, bloody diarrhoea, cholera, haemorrhagic fevers, malaria, measles, meningitis, monkeypox, neonatal tetanus, pertussis, plague, and yellow fever. In 2010, acute respiratory infections, rabies, and typhoid fever were added to the list of weekly reported diseases.
In 2016, dracunculiasis and maternal deaths were also included on the list. The DRC also organises the monthly reporting of 20 endemic and priority health problems. Suspected cases are identified using the WHO clinical case definitions (syndromic approach). Cases are diagnosed and recorded on hard copies by nurses in health centers and by Medical Officers in General Reference Hospitals. The Medical and the Clinical Officers of the private sector are also integrated in IDSR and participate in identification and notification of priority diseases in HZs. Data are reported electronically from the different HZs to the provincial health divisions, and then centralized in the GDDC (Fig. 2). The quality of the data is checked at each level during weekly epidemiological meetings $[10,11]$.

\section{Construction and calculation of the score of IDSR adequacy}

A specific score, the "Score of IDSR Adequacy (SIA)," was designed to assess the level of adequacy of IDSR morbidity data. The level of adequacy of IDSR morbidity data is the ability of these data to reflect real or exact 


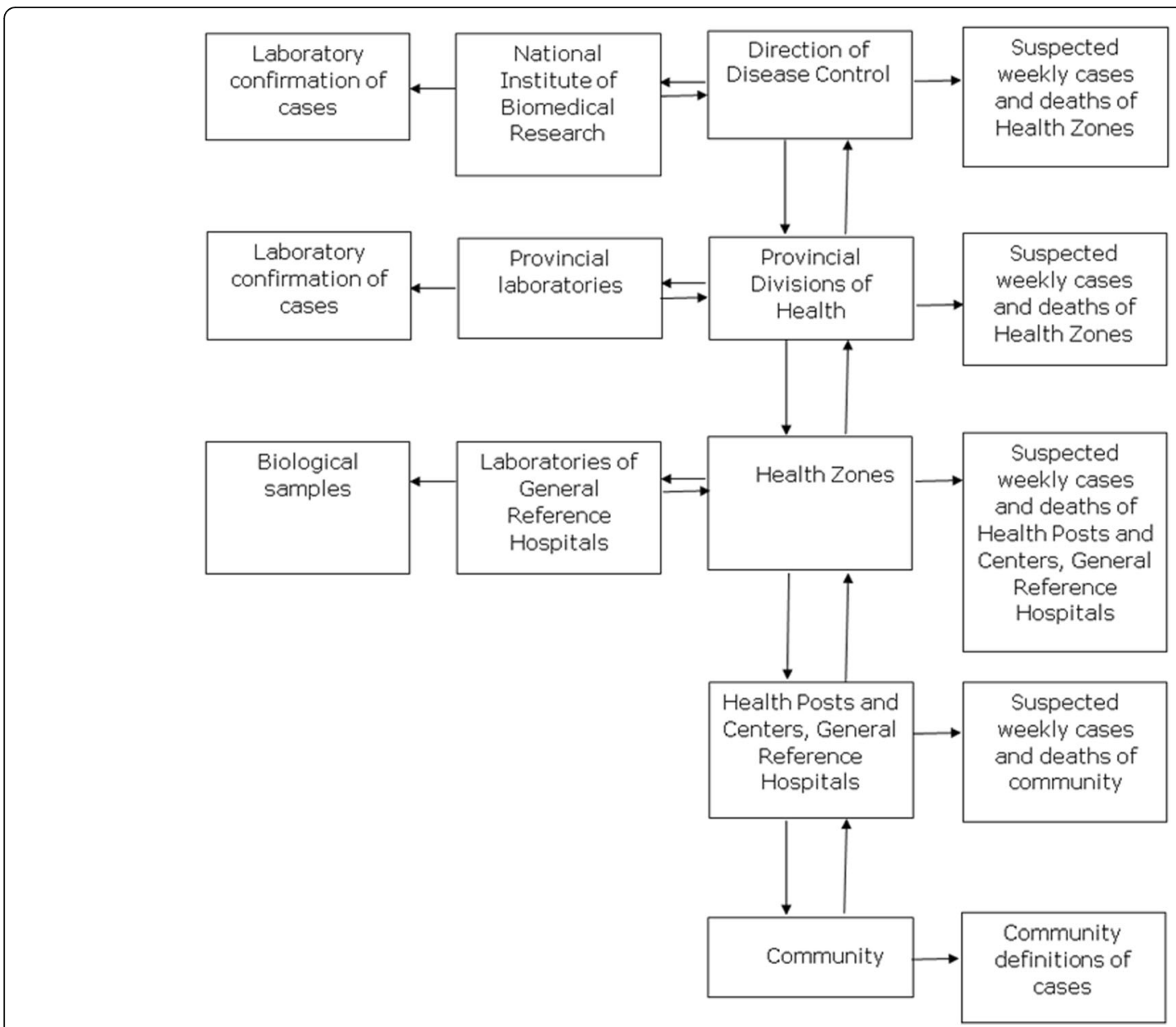

Fig. 2 Flow chart representing the organization of the surveillance system in the DRC

morbidity. No individual clinical data were used to construct the SIA, only bibliographical data. The score was applied to the 15 weekly reported diseases in the DRC, and was constructed according to the following procedures:

1) Literature review focusing on the discrepancies between reported morbidity and actual morbidity; 2) Identification of the determinants of the discrepancies between reported morbidity and actual morbidity; 3 ) Selection of items to be included in the score from the determinants identified in the literature; 4) Construction of the theoretical score; 5) Application of the constructed score to the 15 weekly reported diseases monitored by IDSR surveillance in the DRC; 6) Classification of the 15 diseases using the constructed score; and 7) Performance of a sensitivity analysis on the constructed score. Steps 1 and 2 were conducted using PRISMA guidelines [26]; the PRISMA checklist of items is summarized in Additional file 1: Appendix 1.
1) Literature review focusing on the discrepancies between reported morbidity and actual morbidity Data sources and search strategy

The search was performed in 7 peer-reviewed literature databases: Embase, Medline, Web of Science, Cochrane, Scopus, Cairn.info and Persée, from their inception to December 2016. The keywords in French were: surveillance épidémiologique, données administratives, informations sanitaires, statistiques sanitaires, morbidité rapportée, morbidité réelle et qualité de données. The keywords in English were: epidemiological surveillance, administrative data, health information, health statistics, reported morbidity, real morbidity and data quality. Queries combining the above keywords were performed using the Boolean search operators "AND" and "OR" to identify the most relevant articles. The full search strategy per database is included in Supporting information in Additional file 2: Appendix 2. Technical guides and reports (DRC Ministry of Health, WHO offices, Epicentre) were also included in our review through manual searches. 


\section{Eligibility criteria}

The selected articles focused on: 1) the determinants of the discrepancies between reported morbidity and actual morbidity; and 2) the epidemiological surveillance of infectious diseases in low- and middle-income countries.

Only English- and French-language articles were included in the study.

\section{Study selection}

Two independent reviewers screened the articles on the basis of title and abstract. They then selected the articles that matched the eligibility criteria.

\section{2) Identification of the determinants of the discrepancies} between reported morbidity and actual morbidity Data extraction process and data items

Two independent reviewers used a standardized questionnaire to extract the following bibliographical data in duplicate: name of authors, year of publication, country of study, and determinants of the discrepancies between reported morbidity and actual morbidity. Disagreements between reviewers were solved by consensus.

\section{Synthesis of results}

The determinants of the discrepancies (differences) between "reported morbidity" and "actual morbidity" were defined as major factors that can induce distortions between actual morbidity and health information gathered by health care facilities (reported morbidity). These distortions can occur at different stages of patient care. Three main stages can be distinguished: 1) people's perception of illness and health care; 2) diagnosis by health care providers; and 3) data reporting to the national IDSR database. Based on the literature review, 23 classes of determinants were identified (see Table 1). These classes of determinants are presented in Additional file 3: Table S1.

\section{3) Selection of items to be included in the score from the}

\section{determinants identified in the literature}

To construct the Score of IDSR Adequacy (SIA), we selected determinants with the following 4 characteristics: availability, ability to discriminate, sensitivity, and reproducibility. Availability is the ability of the determinant to be collected easily. Ability to discriminate is the ability of the determinant to represent relatively homogeneous sub-groups. Sensitivity is the ability of the values of the determinant to change if the situation changes. Reproducibility is the ability of the values of the determinant not to change if the situation does not change. Of the determinants detailed in Additional file: Table S1, 12 were selected; these 12 determinants are presented in Table 2. In
Table 1 Classes of determinants of discrepancies of reported morbidity to actual morbidity

\begin{tabular}{|c|c|c|}
\hline $\begin{array}{l}\text { stages of patient } \\
\text { care }\end{array}$ & $\begin{array}{l}\text { Classes of determinants or } \\
\text { potential distorting factors }\end{array}$ & References \\
\hline \multirow{9}{*}{$\begin{array}{l}\text { Perception of the } \\
\text { illness and Health } \\
\text { care access }\end{array}$} & $\begin{array}{l}\text { Form and perceived } \\
\text { severity of illness }\end{array}$ & {$[35-40]$} \\
\hline & $\begin{array}{l}\text { Etiological concept } \\
\text { and type of disease }\end{array}$ & {$[38,40-47]$} \\
\hline & $\begin{array}{l}\text { Individual characteristics } \\
\text { of patients }\end{array}$ & {$[38,43,48-55]$} \\
\hline & $\begin{array}{l}\text { Socio-economic } \\
\text { characteristics of patients }\end{array}$ & {$[38,43,54-65]$} \\
\hline & $\begin{array}{l}\text { Attractiveness factors } \\
\text { of places }\end{array}$ & {$[66-71]$} \\
\hline & $\begin{array}{l}\text { Geographical } \\
\text { accessibility }\end{array}$ & $\begin{array}{l}{[38,42-44,61,} \\
72-75]\end{array}$ \\
\hline & $\begin{array}{l}\text { Characteristics of the } \\
\text { environment }\end{array}$ & {$[66,76-78]$} \\
\hline & Urbanization & [79-83] \\
\hline & Movements of population & [84] \\
\hline \multirow[t]{7}{*}{ Diagnosis } & $\begin{array}{l}\text { Presence of an intervention } \\
\text { program }\end{array}$ & {$[22,85,86]$} \\
\hline & $\begin{array}{l}\text { Functioning of health } \\
\text { services: quality of } \\
\text { service and framework }\end{array}$ & $\begin{array}{l}{[38,44,48,58,} \\
62,87-90]\end{array}$ \\
\hline & Staff competence & {$[44,62,87,91]$} \\
\hline & $\begin{array}{l}\text { Lack of supplementary } \\
\text { diagnosis }\end{array}$ & {$[44,92]$} \\
\hline & $\begin{array}{l}\text { Lack of clinical standardized } \\
\text { decision tree for diagnosing }\end{array}$ & {$[91,93,94]$} \\
\hline & $\begin{array}{l}\text { Difficulty of differential } \\
\text { diagnosis with other } \\
\text { diseases }\end{array}$ & {$[20,31-34]$} \\
\hline & $\begin{array}{l}\text { Spatial distribution of } \\
\text { disease }\end{array}$ & {$[95-97]$} \\
\hline \multirow[t]{7}{*}{ Data reporting } & Staff competence & [84] \\
\hline & $\begin{array}{l}\text { Standardization of data } \\
\text { collection tools }\end{array}$ & {$[84,98]$} \\
\hline & Large volume of work & [31] \\
\hline & Falsification of data & [31] \\
\hline & Typing errors & {$[31,99]$} \\
\hline & $\begin{array}{l}\text { Integration of the } \\
\text { disease } \\
\text { into a national or } \\
\text { global strategy }\end{array}$ & {$[10,100]$} \\
\hline & Characteristic of the response & {$[10,100]$} \\
\hline
\end{tabular}

the SIA score, the selected determinants were named items and the classes of determinants were named dimensions according the score terminology.

\section{4) Construction of the theoretical score}

The response to each SIA item was coded as $0 / 1,0 /$ 2 , or $0 / 1 / 2$. These different code weights were assigned to the SIA items to account for the relative 
Table 2 Score of Integrated Disease Surveillance and Response adequacy (SIA), defined for the present study including: dimensions, items and codes

\begin{tabular}{|c|c|c|}
\hline Dimension & Item & Code $^{\#}$ \\
\hline \multirow[t]{5}{*}{ Form \& perceived severity of illness* } & Incubation period & $0=>14$ days $; 1=7-14$ days; $2=<7$ days \\
\hline & Onset of disease & $0=$ Mild $; 2=$ Severe with symptoms \\
\hline & Symptoms in the acute phase & $0=$ Mild $; 2=$ Severe \\
\hline & Contagiousness & $\begin{array}{l}0=\text { Low } ; 1=\text { Moderate; } \\
2=\text { High }\end{array}$ \\
\hline & Death rate (\%) without Treatment & $0=<5 ; 1=6-19 ; 2=>=20$ \\
\hline Etiological concept \& disease type ${ }^{* *}$ & Disease Local Name & $\begin{array}{l}0=\text { Without } 1 \text { = Changing according localities; } \\
2=\text { Shared by localities }\end{array}$ \\
\hline \multirow[t]{2}{*}{ Differential diagnosis with other diseases** } & $\begin{array}{l}\text { Number of epidemics reported each } \\
\text { year during the last five years }\end{array}$ & $\begin{array}{l}0=\text { Less than } 2 ; 1=2 \text { to } 4 ; \\
2=5\end{array}$ \\
\hline & $\mathrm{PPV}^{* * *}$ & $\begin{array}{l}0=<20 \% ; 1=20-50 \% \\
2=>=50 \%\end{array}$ \\
\hline Spatial distribution of disease $\mathrm{e}^{* *}$ & $\begin{array}{l}\text { Proportion of health zones affected } \\
\text { by epidemics of each of the } 15 \\
\text { diseases (\%). }\end{array}$ & $\begin{array}{l}0=\text { less than } 20 \% \\
1=\text { more than } 20 \%\end{array}$ \\
\hline \multirow[t]{2}{*}{ Integration of the disease into a national or global strategy** } & Internationally funded research & $0=$ Without; $1=$ With \\
\hline & $\begin{array}{l}\text { National or International eradication } \\
\text { programs }\end{array}$ & $0=$ Not $; 1=$ yes \\
\hline Response Characteristic* & Timely Response & $\begin{array}{l}0=\text { delayed response; } \\
1=\text { Immediate }\end{array}$ \\
\hline
\end{tabular}

$\mathrm{PPV}=$ Positive predictive value

a $=$ Value Numbers

$\mathrm{b} *=$ Criteria intrinsically related to pathology

c $* *=$ Criteria changing between countries and over time

influence of people's perception of illness and health care (36). The highest code values ( 2 or 1 for items coded as $0 / 1$ ) were attributed to the items that facilitate people's perception of illness and health care, diagnosis by health care providers, and/or data reporting. For each disease, the SIA was the sum of the code values for all weighted items. The theoretical SIA ranged from 0 to 20 points (Table 2). The coding of each SIA item for cholera is shown in Additional file 4: Appendix 3.

\section{5) Application of the constructed score to the 15 weekly reported diseases monitored by IDSR surveillance in the DRC}

The SIA was calculated for the 15 weekly reported diseases (acute flaccid paralysis, acute respiratory infections, bloody diarrhoea, cholera, haemorrhagic fevers, malaria, measles, meningitis, monkeypox, neonatal tetanus, pertussis, plague, rabies, typhoid fever, and yellow fever) [14]. We focused on these diseases because they were the only ones to be monitored by IDSR surveillance in the DRC prior to 2015. The distribution of observed responses to each item (codes) was described. Redundancy of items in each dimension was assessed using the Kappa coefficient.

\section{6) Classification of the 15 diseases using the constructed score}

The score was discretized using both the Jenks method and the natural thresholds method. The Jenks method provided the most homogeneous categories using an iterative procedure that allowed for minimizing intra-class variance and for maximizing inter-class variance. It was the most suitable for discretizing the overall score for each disease. The natural thresholds method categorized the 15 diseases taking into account the discontinuities of the series. [27, 28]. It was performed as a comparative method to confirm the robustness of our analysis. These two discretization procedures allowed for assessing the quality of the data produced for each of the 15 weekly reported diseases according to their calculated score.

The Jenks method and the natural thresholds methods were selected because they help to constitute homogenous categories. In our study, they allowed for classifying diseases into 3 categories or types: Types I, II, and III. Type I is composed of diseases with a score greater than or equal to 14, (high score). This score indicates good adequacy of IDSR morbidity data, meaning that the data can be used for epidemiological research or public health purposes. Type II is composed of diseases with a score ranging from 8 to 14 (moderate score). This score indicates fair adequacy of IDSR morbidity data, 
meaning that the data can be used after adjustment for epidemiological research or public health purposes. Type III is composed of diseases with a score smaller than 8 (low score). This score indicates low or non-adequacy of IDSR morbidity data, meaning that the data cannot be used for epidemiological research or public health purposes.

\section{7) Performance of a sensitivity analysis on the constructed score}

To check the robustness of the score, a sensitivity analysis was performed in two ways: 1) by iteratively removing one item at a time; and 2) by modifying the numerical values of the item codes (values $0,1,2$ changed to 0,1 , to 0,2 , 4, etc.). Removing one item at a time allowed us to assess the potential major effect of each item on the overall score, and modifying the item code values allowed us to assess the effects of the code weights. After each modification, the score was recalculated, and the newly obtained score was discretized using the Jenks method. For each of the 15 diseases, the new score rankings and categories were compared to the initial score rankings and categories to ensure that no significant variation had occurred.

\section{Characteristics of the selected studies}

The protocol search strategy yielded 2254 abstracts. Of these, 853 duplicate records were removed. The 1401 remaining abstracts were screened, and 1101 were excluded due to non-relevance. Of the 300 remaining articles with full texts, 71 matched the inclusion criteria (Fig. 1). The 71 included articles were published between the years 1974 and 2014. Of these, 41 articles focused on infectious diseases and 54 on low- and middle-income countries; 45 were written in English; and 44 were published after the year 2000 (date of initiation of IDSR in Africa). Five IDSR technical guides [11-14] and 30 technical reports $(n=30)$ were also included in our bibliographical research (Fig. 3). These documents provided crucial information on the context and factors favouring the onset of outbreaks, the operational case definitions, the local names of diseases, the types of intervention, the number of epidemics reported each year by DRC region, the biological confirmation of cases, and the modalities of epidemic response.

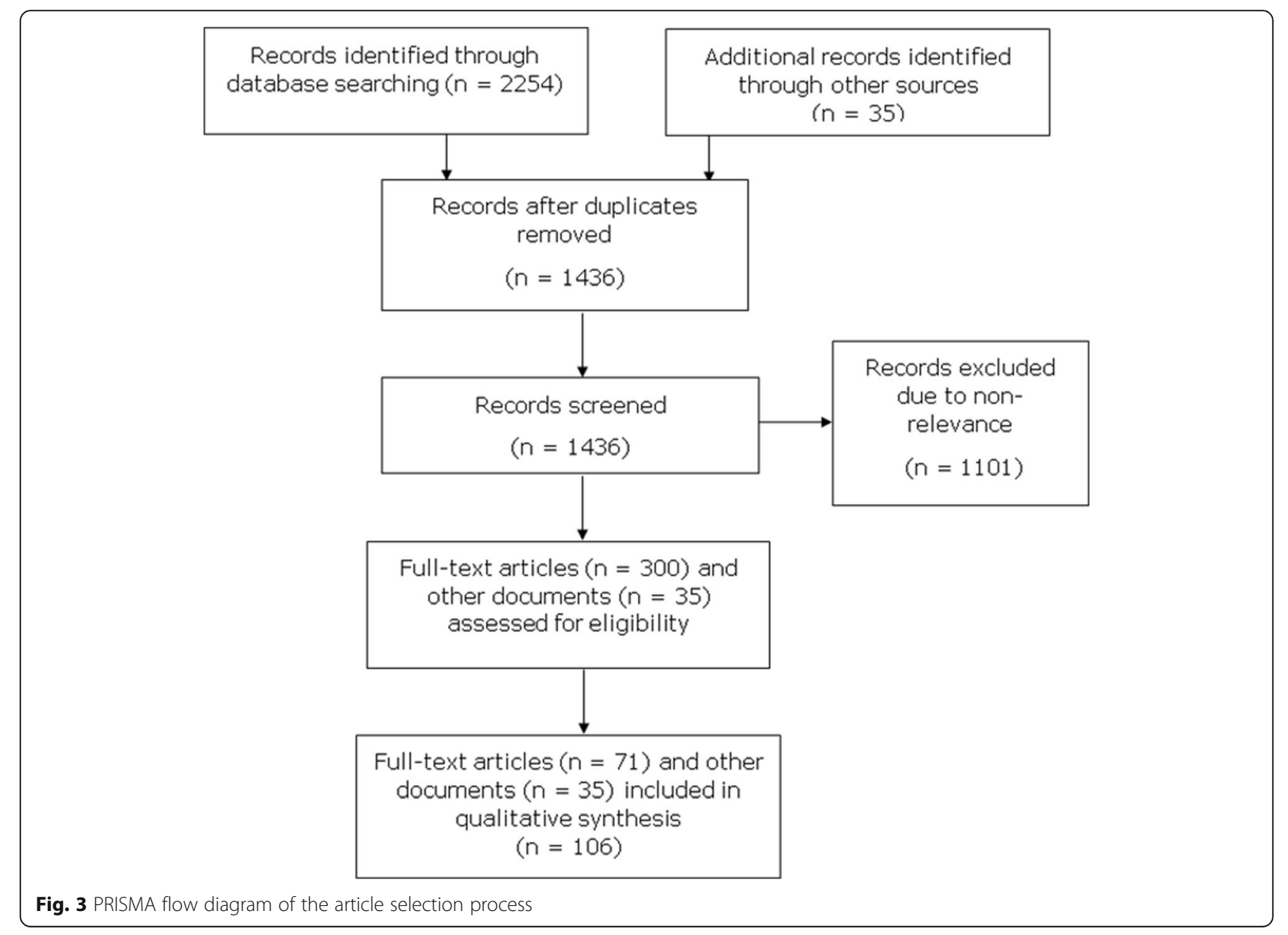




\section{Synthesis of results}

Twelve of the identified determinants were selected to be used as SIA items. These 12 items were related to the six dimensions of the SIA (one to 5 items per dimension) (Table 2). Six items are linked to people's perception of illness and health care: incubation period, onset of disease, symptoms in the acute phase, contagiousness, death rate (\%) without treatment, and local disease name. Three items are linked to diagnosis: number of epidemics reported each year during the last five years, positive predictive value (PPV), and proportion of health zones affected by epidemics of each of the 15 diseases (\%). The last three items are linked to data reporting: internationally funded research, national or international eradication programs, and timely response.

\section{Results}

When the SIA was applied to the 15 weekly reported diseases, SIA values ranged from 4 (rabies) to 19 points (cholera). The mean score was 10.7 points (Table 3). Agreement between items in each dimension ranged from 0.03 to 0.47 (Kappa coefficients). All numerical code values proposed for each item were used at least once.

After discretization, 3 categories of diseases were identified as follows (Fig. 4):
- Type 1: High score (value > = 14) (good adequacy: IDSR morbidity data can be used for epidemiological research or public health purposes); this category included cholera, measles, haemorrhagic fevers and bloody diarrhoea;

- Type 2: Moderate score (value $>=8$ and $<14$ ) (fair adequacy: IDSR morbidity data can be used after adjustment for epidemiological research or public health purposes); this category included neonatal tetanus, monkeypox, acute flaccid paralysis pertussis, meningitis, acute respiratory infections and yellow fever;

- Type 3: Low score: (value $<8$ ) (low or nonadequacy: IDSR morbidity data cannot be used for epidemiological research or public health purposes); this category included malaria, typhoid fever and rabies.

\section{Additional analysis}

The results of the sensitivity analysis, both by iteratively removing one item at a time and by modifying the item code values, are presented in Tables 4 and 5. Iteratively removing one item at a time did not lead to changes in the score ranking, as the highest-ranking diseases were still cholera and measles (19 and 16, respectively) and the lowest-ranking ones were still yellow fever, malaria,

Table 3 Calculation of the score of IDSR adequacy among 15 weekly reported diseases by the Integrated Disease Surveillance and Response (IDSR) WHO program implemented in the Democratic Republic of Congo

\begin{tabular}{|c|c|c|c|c|c|c|c|c|c|c|c|c|c|c|}
\hline \multirow[t]{2}{*}{ Disease } & \multicolumn{3}{|c|}{ F\&P Severity } & \multicolumn{3}{|l|}{ ECT } & \multicolumn{2}{|l|}{$\mathrm{DD}$} & \multirow{2}{*}{$\begin{array}{l}\text { Spatial D } \\
\text { PAE }\end{array}$} & \multicolumn{2}{|c|}{ Strategy } & \multirow{2}{*}{$\begin{array}{l}\text { Response } \\
\text { TR }\end{array}$} & \multirow[t]{2}{*}{ Total } & \multirow[t]{2}{*}{$\%$} \\
\hline & $\overline{\mathrm{IP}}$ & OD & SAP & Cont & DRT & DLN & NER & PPV & & $\overline{I F R}$ & NIEP & & & \\
\hline Cholera & $2^{*}$ & 2 & 2 & 2 & 2 & 2 & 2 & 1 & 1 & 1 & 1 & 1 & 19 & 95 \\
\hline Measles & 1 & 0 & 2 & 2 & 2 & 2 & 2 & 1 & 1 & 1 & 1 & 1 & 16 & 80 \\
\hline $\mathrm{BD}$ & 2 & 2 & 2 & 1 & 1 & 1 & 1 & 1 & 1 & 1 & 0 & 1 & 14 & 70 \\
\hline $\mathrm{HF}$ & 1 & 2 & 2 & 2 & 2 & 1 & 0 & 2 & 0 & 1 & 0 & 1 & 14 & 70 \\
\hline NT & 2 & 0 & 2 & 0 & 2 & 1 & 0 & 2 & 1 & 1 & 1 & 0 & 12 & 60 \\
\hline MPX & 1 & 0 & 2 & 2 & 1 & 1 & 2 & 2 & 0 & 1 & 0 & 0 & 12 & 60 \\
\hline AFP & 0 & 0 & 2 & 2 & 1 & 1 & 0 & 1 & 1 & 1 & 1 & 1 & 11 & 55 \\
\hline Pertussis & 1 & 0 & 2 & 2 & 1 & 1 & 0 & 1 & 1 & 1 & 0 & 0 & 10 & 50 \\
\hline Plague & 2 & 0 & 0 & 2 & 2 & 1 & 1 & 1 & 0 & 0 & 0 & 1 & 10 & 50 \\
\hline MNG & 2 & 0 & 0 & 2 & 2 & 0 & 1 & 0 & 1 & 1 & 0 & 1 & 10 & 50 \\
\hline ARI & 2 & 0 & 0 & 1 & 2 & 1 & 1 & 1 & 1 & 0 & 0 & 0 & 9 & 45 \\
\hline YF & 2 & 0 & 2 & 2 & 2 & 0 & 0 & 0 & 0 & 0 & 0 & 0 & 8 & 40 \\
\hline Malaria & 1 & 0 & 0 & 0 & 2 & 1 & 0 & 1 & 1 & 1 & 0 & 0 & 7 & 35 \\
\hline TF & 1 & 0 & 0 & 1 & 2 & 0 & 0 & 0 & 1 & 0 & 0 & 0 & 5 & 25 \\
\hline Rabies & 0 & 0 & 0 & 0 & 2 & 1 & 0 & 0 & 1 & 0 & 0 & 0 & 4 & 20 \\
\hline
\end{tabular}

AFP Acute flaccid paralysis, ARI Acute respiratory infections, BD Bloody diarrhoea, Cont., Contagiousness, DD Differential Diagnosis, DLN Disease Local Name, DRT Death rate (\%) without Treatment, ECT Etiological concept and type of disease, F\&P Severity, Form and perceived severity, HF Hemorrhagic fevers, IFR Internationally funded research, IP Incubation period, MNG Meningitis, MPX Monkeypox, NER Number of epidemics reported each year during the last five years, NIEP National/International eradication programs, NT Neonatal tetanus, OD Onset disease, PAE Proportion of health zones affected by epidemics of each of the 15 diseases (\%), PPV Positive predictive value, Response, Response Characteristic, SAP symptoms in the acute phase, Spatial D, Spatial distribution of disease, Strategy, Disease \& national or global strategy, Response, Response Characteristic, TF Typhoid fever, TR Timely Response, YF Yellow fever

a * All values in the colons refer to the Table 2 


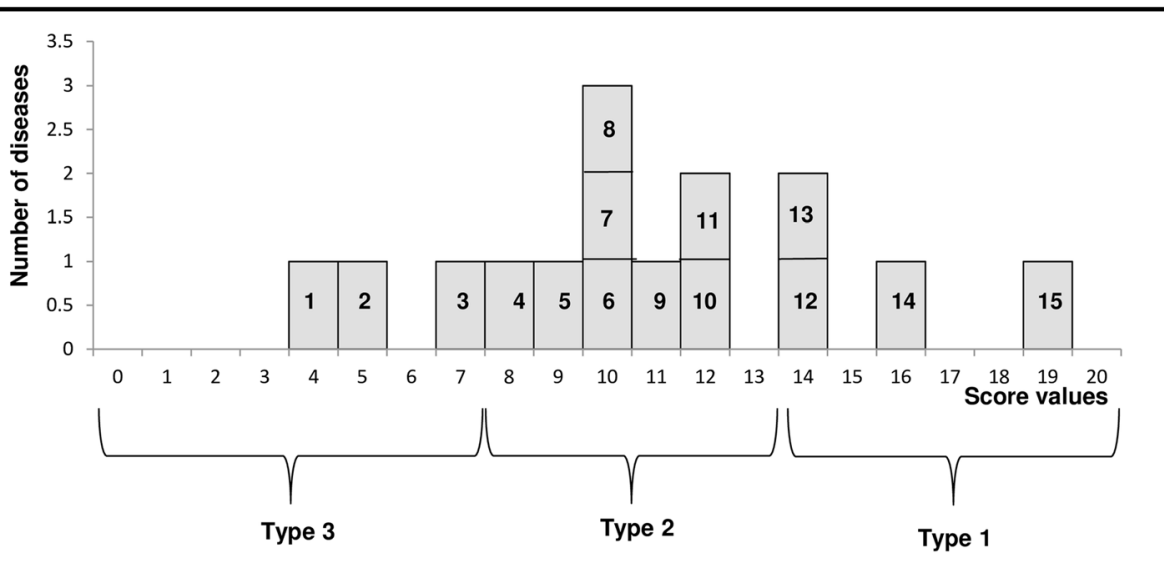

Fig. 4 Classification of the 15 weekly reported diseases monitored by IDSR surveillance in the DRC (according to the Jenks method), ${ }^{\text {aType }} 1$,

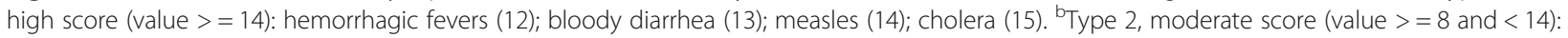
yellow fever (4); acute respiratory infections (5); meningitis (6); plague (8); pertussis (8); acute flaccid paralysis (9); monkeypox (10); neonatal tetanus (11). ${ }^{\circ}$ Type 3, low score (value < 8): rabies (1); typhoid fever (2); malaria (3). ${ }^{d}$ Discretization using the natural thresholds method yielded almost the same classification, except in the case of malaria, which was classified as Type 2 instead of Type 3

Table 4 Sensitivity analysis of score of IDSR adequacy by removing iteratively one item at a time of calculated codes of the 15 weekly reported diseases by the IDSR in DRC

\begin{tabular}{|c|c|c|c|c|c|c|c|c|c|c|c|c|c|c|}
\hline \multirow[t]{2}{*}{ Ty. } & \multirow[t]{2}{*}{ Disease } & \multirow[t]{2}{*}{ Score } & \multicolumn{12}{|c|}{ Removed item ** } \\
\hline & & & $\mathrm{IP}$ & OD & SAP & Cont & DRT & DLN & NER & PPV & PAE & IFR & NIEP & $\mathrm{TR}$ \\
\hline \multirow[t]{4}{*}{ I } & Cholera & $19^{*}$ & 17 & 17 & 17 & 17 & 17 & 17 & 17 & 18 & 18 & 18 & 18 & 18 \\
\hline & Measles & 16 & 15 & 16 & 14 & 14 & 14 & 14 & 14 & 15 & 15 & 15 & 15 & 15 \\
\hline & $\mathrm{BD}$ & 14 & $13^{\#}$ & $12^{\#}$ & $12^{\#}$ & 13 & 13 & 13 & 14 & 13 & 14 & 13 & 14 & 13 \\
\hline & $\mathrm{HF}$ & 14 & $12^{\#}$ & $12^{\#}$ & $12^{\#}$ & 12 & 12 & 13 & 13 & $12^{\#}$ & 13 & 13 & 14 & 13 \\
\hline \multirow[t]{8}{*}{$\|$} & NT & 12 & 11 & 12 & 10 & 12 & 11 & 11 & 12 & 10 & 12 & 11 & 12 & 12 \\
\hline & MPX & 12 & $10^{\wedge}$ & 12 & 10 & 10 & 10 & 11 & $10^{\wedge}$ & 10 & 11 & 11 & 11 & 12 \\
\hline & AFP & 11 & $11^{\wedge}$ & 11 & $9 \wedge$ & 9 & 10 & 10 & $11 \wedge$ & 10 & 10 & 10 & 10 & 10 \\
\hline & Pertussis & 10 & 9 & 10 & $10 \wedge$ & 8 & 9 & 10 & 10 & 10 & 10 & 10 & 10 & 10 \\
\hline & Plague & 10 & $8^{\#}$ & 10 & $10^{\wedge}$ & 8 & 8 & 9 & 9 & 9 & 9 & 9 & 10 & 9 \\
\hline & MNG & 10 & $8^{\#}$ & 10 & $8^{\wedge}$ & 8 & 8 & 9 & 9 & 9 & 9 & 9 & 10 & 9 \\
\hline & ARI & 9 & $7^{\#}$ & 9 & $9 \wedge$ & 8 & 7 & 8 & 8 & 8 & 8 & 9 & 9 & 9 \\
\hline & YF & 8 & $6^{\#}$ & $8^{\#}$ & $6 \wedge$ & $6 \wedge$ & $6^{\#}$ & 8 & 8 & 8 & 8 & 8 & 8 & 8 \\
\hline \multirow[t]{3}{*}{ III } & Malaria & 7 & 6 & 7 & $7 \wedge$ & $7^{\wedge}$ & 5 & 6 & 7 & 6 & 6 & 6 & 7 & $7^{\#}$ \\
\hline & TF & 5 & 4 & 5 & 5 & 4 & 3 & 5 & 5 & 5 & 4 & 5 & 5 & 5 \\
\hline & Rabies & 4 & 4 & 4 & 4 & 4 & 2 & 3 & 4 & 4 & 3 & 4 & 4 & 4 \\
\hline
\end{tabular}

AFP Acute flaccid paralysis, ARI Acute respiratory infections, BD Bloody diarrhoea, Cont. Contagiousness, DLN Disease Local Name, DRT Death rate (\%) without Treatment, HF Hemorrhagic fevers, IFR internationally funded research, IP Incubation period, MNG Meningitis, MPX Monkeypox, NER Number of epidemics reported each year during the last five years, NIEP National/International eradication programs, NT Neonatal tetanus, OD Onset disease, PAE Proportion of health zones affected by epidemics of each of the 15 diseases (\%), PPV Positive predictive value, SAP symptoms in the acute phase, Response Response Characteristic, TF Typhoid fever, TR Timely Response, YF Yellow fever

a * All values in the colons refer to the Table 3

b** see Table 2

c Type I: SIA > = 14; Type II: SIA = 8-13; Type III: SIA < 8

d $\wedge$, Number in bold denote SIA value that changes the rank of the disease in the same type

e \#, Number in bold denote SIA value that changes the type of disease 
Table 5 Sensitivity analysis of score of IDSR adequacy by modifying the numerical values of the item calculated codes of the 15 weekly reported diseases by the IDSR in DRC

\begin{tabular}{|c|c|c|c|c|c|c|c|}
\hline \multirow[t]{2}{*}{ Ty. } & \multirow[t]{2}{*}{ Disease } & \multirow[t]{2}{*}{ Score } & \multicolumn{5}{|c|}{ Modifying the numerical values of the item codes ** } \\
\hline & & & CC1 & CC2 & CC3 & CC4 & CC5 \\
\hline \multirow[t]{4}{*}{ । } & Cholera & $19^{*}$ & 17 & 23 & 27 & 12 & 32 \\
\hline & Measles & 16 & 15 & 20 & 24 & 11 & 29 \\
\hline & $\mathrm{BD}$ & 14 & $12^{\#}$ & $17^{\#}$ & $20^{\#}$ & $9 \wedge$ & $22^{\#}$ \\
\hline & HF & 14 & $12^{\#}$ & $16^{\#}$ & $18^{\#}$ & $11 \wedge$ & $22^{\#}$ \\
\hline \multirow[t]{8}{*}{$\|$} & NT & 12 & 11 & 15 & $20^{\wedge}$ & 8 & 21 \\
\hline & MPX & 12 & 11 & $13^{\wedge}$ & 18 & 8 & 21 \\
\hline & AFP & 11 & 10 & 15 & 14 & $9 \wedge$ & 19 \\
\hline & Pertussis & 10 & 10 & 13 & $18^{\wedge}$ & 8 & $20^{\wedge}$ \\
\hline & Plague & 10 & 10 & 12 & $17^{\wedge}$ & 7 & $20 \wedge$ \\
\hline & MNG & 10 & 9 & 11 & 14 & 7 & 17 \\
\hline & ARI & 9 & 9 & $10^{\#}$ & $16 \wedge$ & 7 & $18^{\wedge}$ \\
\hline & YF & 8 & $7^{\#}$ & $8^{\#}$ & $13^{\#}$ & $4^{\#}$ & $13^{\#}$ \\
\hline \multirow[t]{3}{*}{ III } & Malaria & 7 & 7 & $9 \wedge$ & 11 & $6 \wedge$ & $14 \wedge$ \\
\hline & TF & 5 & 5 & 6 & 9 & 4 & 10 \\
\hline & Rabies & 4 & 4 & 5 & 7 & 3 & 8 \\
\hline
\end{tabular}

AFP Acute flaccid paralysis, ARI Acute respiratory infections, BD Bloody diarrhoea, Cont. Contagiousness, DLN Disease Local Name, DRT Death rate (\%) without Treatment, HF Hemorrhagic fevers, IFR internationally funded research, IP Incubation period, MNG Meningitis, MPX Monkeypox, NER Number of epidemics reported each year during the last five years, NIEP National/International eradication programs, NT Neonatal tetanus, OD Onset disease, PAE Proportion of health zones affected by epidemics of each of the 15 diseases (\%), PPV Positive predictive value, SAP symptoms in the acute phase, Response Response Characteristic, TF Typhoid fever, TR Timely Response, YF Yellow fever

a * All values in the colons refer to the Table 3

b ** see Table 2

c Type I: SIA > = 14; Type II: SIA = 8-13; Type III: SIA $<8$

d $\wedge$, Number in bold denote SIA value that changes the rank of the disease in the same type

e \#, Number in bold denote SIA value that changes the type of disease

typhoid fever, and rabies (8, 7, 5, and 4, respectively). Modifying the item code values led to minor changes in the score ranking of the other pathologies (differences of no more than one or 2 ranks). However, the same 3 categories resulted from discretization. Minor changes were observed when the following items were iteratively removed: "incubation period," "onset of disease," and "symptoms in the acute phase." No changes were observed when the other items were removed, and the distribution of the diseases into the 3 categories was only slightly modified.

\section{Discussion}

The application of the SIA to the 15 weekly reported diseases monitored by IDSR surveillance in the DRC yielded 3 categories or types: high score or good adequacy (value $>=14$; usable data), moderate score or fair adequacy (value $>=8$ and $<14$; usable data after adjustment), and low score or low or non-adequacy (value $<8$; non-usable data).

Overall, our examination of studies from a wide range of disciplines, as well as of IDSR technical guides and reports of outbreak investigations, gave a strong foundation to this study. The SIA is the outcome of sound interdisciplinary work, combining the expertise of specialists in the fields of integrative health geography, public health, epidemiology, infectious diseases, and medical anthropology. It also draws on 20 years of experience and feedback from field practitioners responsible for care structures in rural areas of the DRC.

The SIA was constructed using a pragmatic and robust assessment method. The agreement between items varied from low to moderate, indicating a low redundancy of items in each dimension. All the code values assigned to SIA items were used at least once. The sensitivity analysis confirmed the robustness of the score: neither the score ranking nor the classification of the different diseases were modified when iteratively removing one item at a time, or when modifying the item code values. However, for some Type-2 diseases, the score ranking was slightly modified, even as the classification remained unchanged.

According to the PRISMA checklist, there should be no bias within or across studies included in systematic reviews. Our systematic review was not concerned by this requirement because no meta-analysis was included. Only qualitative studies were screened for determinants that can induce discrepancies between reported morbidity and actual morbidity. 
Other methods have been proposed to study the adequacy of reported morbidity in reflecting actual morbidity. However, these methods focused on a single disease or on a limited number of diseases [19, 20, 23]. To our knowledge, the SIA is the first method that can apply to all 15 weekly reported diseases monitored by IDSR surveillance in the DRC. As such, it allows for the extensive assessment of the quality of data collected on a wide range of diseases, including neglected diseases that are not integrated into major global strategies (like pertussis or plague).

Our study found coherence in the value of the score obtained for each of the diseases. The SIA confirms the low quality of data produced on diseases (such as malaria) monitored using syndromic surveillance [22, 29]. Moreover, it allows for analysing data on certain pathologies (neonatal tetanus, acute respiratory infections, and rabies) that are less frequently investigated. Unlike previous attempts at assessing data quality (usually data on a single health problem or disease) with tools using binary variables (presence/absence, positive/negative, or yes/no) [20], the SIA can quantify the adequacy of data in reflecting the actual morbidity of each monitored disease. It is therefore one of the only tools available to pragmatically assess the quality of IDSR morbidity data. This can be of great relevance to the various users and actors involved in the implementation of surveillance and response strategies like the IDSR.

Nevertheless, this study has limitations that must be acknowledged. Our literature review may have missed some relevant determinants that could have been included in the score. However, only currently available and accessible information in the DRC were used to construct the SIA. It is therefore unlikely that an additional determinant would have affected the consistency and validity of the score.

Another limitation of our study is that the SIA was applied to weekly reported diseases that are monitored using the syndromic approach. The code values of 3 items (number of epidemics reported each year during the last 5 years; PPV; and proportion of health zones affected by epidemics of each of the 15 diseases) would likely change if the data on these diseases concerned biologically confirmed cases. It is therefore also likely that the score ranking of the different diseases would change if the SIA were applied to diseases not monitored using the syndromic approach.

In our study, cholera had the highest score among all Type-1 diseases. The good adequacy of IDSR cholera data in reflecting actual cholera morbidity has already been demonstrated in a study by Bompangue et al. This study examined the spatial and temporal dynamic of cholera outbreaks using IDSR morbidity data: it identified lacustrine sanctuary areas as the site of emergence of all cholera outbreaks in the DRC $[16,17]$. These findings have led to significant advances in the understanding of the mechanisms involved in the spread and recurrence of cholera outbreaks. They have also prompted the DRC Ministry of Health to adjust the national strategy for cholera control by targeting cholera sanctuary areas [18]. The success of this adjusted strategy may be seen as a retroactive validation of the quality of IDSR data on this disease. This is in line with our findings, whereby IDSR data on cholera have a high level of adequacy in reflecting actual cholera morbidity, as calculated using the SIA.

Similarly, the SIA classification of measles as a Type-1 disease corroborates the findings of a study by Fasin et al. [20]. Of the five diseases or health conditions analysed in this study (chickenpox, hepatoma, anaemia, malnutrition and measles), only data on measles morbidity had a good level of adequacy in reflecting actual measles morbidity. This pathology was also the only one to show both satisfactory relevance and quality [20]. These findings are unsurprising because in low and middle-income countries, where measles prevalence remains high, health workers are well-equipped to recognize and produce a clinical diagnosis of the disease and diagnosis is oriented in the absence of prior vaccination [30].

Adjusted data on monkeypox, a Type-2 disease as per the SIA, have been used in a study conducted in the DRC by Hoff et al. This study using IDSR morbidity data on monkeypox proposed two adjustment methods: a comparison of monkey pox with two control diseases (acute flaccid paralysis and neonatal tetanus), and a scenario tree model to estimate the proportion of potentially lost cases in the DRC health system [23].

Our study indicates that IDSR morbidity data on yellow fever, malaria, typhoid fever, and rabies (Type-3 diseases) should not be used for epidemiological research or public health purposes, due to their low level of adequacy in reflecting actual morbidity. Until 2014, the clinical and presumptive diagnosis of malaria based solely on fever likely induced many false positives. Several infectious diseases can cause fever, which may explain the large gap between supposed and actual cases of malaria [22, 29, 31]. The same applies to yellow fever and typhoid fever, which can be confused with several other pathologies when they are syndromically diagnosed. One of the main reasons for the misdiagnosis of rabies, and for the limited use of data on the disease, may be its long incubation period. It is indeed difficult for health workers to link a dog bite that occurred 1 to 3 months earlier to recent symptoms. The clinical diagnosis of rabies can also be difficult if the specific signs of hydrophobia or aerophobia are not present $[32,33]$. Lastly, bat-acquired cases of rabies may be 
missed because health care providers fail to inquire into the history of bat bites [34].

\section{Conclusion}

Our study found that the quality of IDSR morbidity data is highly variable from one disease to another. If confirmed, these findings could prompt a revision of the IDSR strategy as it is applied in low- and middle-income countries. The different algorithms of disease surveillance could be reconsidered and improved, especially those that rely on a syndromic approach. Lastly, the SIA could be applied: 1) to monthly reported diseases; and 2) to weekly reported diseases in other low- and middle-income countries that are not monitored using a syndromic approach.

\section{Additional file}

Additional file 1: Appendix 1. PRISMA 2009 Checklist. A checklist includes 27 items deemed essential for transparent reporting of a systematic review. (DOCX $32 \mathrm{~kb}$ ). (DOCX $31 \mathrm{~kb}$ )

Additional file 2: Appendix 2. . Database search strategies. Description of data: Appendix 2 includes the search terms for the epidemiological surveillance, administrative data, health information, health statistics, reported morbidity, real morbidity and data quality. (DOCX $35 \mathrm{~kb}$ )

Additional file 3: Table S1. Classes and determinants of discrepancies of reported morbidity to actual morbidity. A table includes all determinants of discrepancies or differences of reported morbidity to actual morbidity identified during literature review and their belonging classes. (DOCX $25 \mathrm{~kb}$ )

Additional file 4: Appendix 3. Illustration of coding of each SIA item of cholera. Appendix 3 shows the assignment of code values of each item and the calculation the score for cholera.(DOCX $20 \mathrm{~kb}$ )

\section{Abbreviations}

AFP: Acute flaccid paralysis; ARl: Acute respiratory infections; BD: Bloody diarrhoea; Cont.: Contagiousness; DD: Differential Diagnosis; DLN: Disease Local Name; DRC: Democratic Republic of Congo; DRT: Death rate (\%) without Treatment; ECT: Etiological concept and type of disease; F\&P Severity: Form and perceived severity; GDDC: General Direction of Disease Control; HF: Hemorrhagic fevers; IDSR: Integrated Disease Surveillance and Response; IFR: internationally funded research; IP: Incubation period; MNG: Meningitis; MPX: Monkeypox; NER: Number of epidemics reported each year during the last five years; NIEP: National/International eradication programs; NT: Neonatal tetanus; OD: Onset disease; PAE: Proportion of health zones affected by epidemics of each of the 15 diseases (\%); PPV: Positive predictive value; PRISMA: Preferred Reporting Items for Systematic reviews and Meta-Analyses; Response: Response Characteristic; SAP: Symptoms in the acute phase; SIA: Score of IDSR Adequacy; Spatial D: Spatial distribution of disease; TF: Typhoid fever; TR: Timely Response; WHO AFRO: WHO Regional Office for Africa; WHO: World Health Organization; YF: Yellow fever

\section{Acknowledgments}

We thank all the members of the Research and Training Unit on the Ecology and Control of Infectious Diseases of the University of Kinshasa and all the members of the Clinical Methodology Center of CHU Besançon in France for helping to the drafting of this article.

\section{Funding}

The project was funded by the PICS CNRS France 2015 with number System: 263320.

\section{Availability of data and materials}

The datasets supporting the conclusions of this article are included within the article and its additional files.

\section{Authors' contributions}

$\mathrm{BM}, \mathrm{DB}, \mathrm{PH}$ and $\mathrm{FM}$ contributed to the conception and design of the study. BM acquired the data. BM, JPG, GS and JJM analyzed and interpreted the data. BM, DB, PH and FM drafted the manuscript and all authors revised it for important intellectual content. All authors reviewed and edited multiple drafts and approved the final manuscript for publication.

\section{Ethics approval and consent to participate}

This research was not considered human subjects research. Therefore, consultation of an ethics committee and consent to participate is not required.

\section{Consent for publication \\ Not applicable.}

\section{Competing interests}

The authors declare that they have no competing interests.

\section{Publisher's Note}

Springer Nature remains neutral with regard to jurisdictional claims in published maps and institutional affiliations.

\section{Author details}

${ }^{1}$ Service de Microbiologie, Faculté de Médecine, Université de Kinshasa, Kinshasa, Democratic Republic of Congo. ${ }^{2}$ Laboratoire

Chrono-Environnement, UMR 6249 CNRS, Université de Bourgogne Franche-Comté, Besançon, France. ${ }^{3}$ UMR 912 SESSTIM, INSERM, IRD, U2, Université d'Aix-Marseille, Strasbourg, France. ${ }^{4}$ Department of Microbiology and Immunology, Division of Biomedical Graduate Research Organization, Georgetown University School of Medicine, 4000 Reservoir Road, Washington, D.C., NW 20057, USA. ${ }^{5}$ Université Paris Ouest Nanterre, Paris, France. ${ }^{6}$ Institut National de Recherche Biomédicale, Kinshasa, Democratic Republic of Congo. ${ }^{7}$ Centre Hospitalier Universitaire de Besançon, UMETh, Besançon, France.

Received: 20 December 2018 Accepted: 8 May 2019

Published online: 22 May 2019

\section{References}

1. Bhutta ZA, Johannes S, Zohra SL, Rehana AS, Jai KD. Global burden, distribution, and interventions for infectious diseases of poverty. Infectious Diseases of Poverty. 2014;3(1):21.

2. World Health organization: Regional Office for Africa. Atlas of African Health Statistics 2016. Health situation analysis of the African Region, 2015. Available from: https://apps.who.int/iris/handle/10665/206547. (Last Accessed on 10 Dec 2016).

3. Haidong W, Naghavi M, Allen C et al. Global, Regional, and National Life Expectancy, All-Cause Mortality, and Cause-Specific Mortality for 249 Causes of Death, 1980-2015: A Systematic Analysis for the Global Burden of Disease Study 2015. The Lancet. 2016; 388(10053):1459-1544.

4. World Health organization: Regional Office for Africa. The health of the people: what works? - The African Regional Health Report, 2014;6-14. Available from: https://www.who.int/bulletin/africanhealth/en/. (Last Accessed on 5 Dec 2016). ISBN: 9789290232612.

5. Goma Epidemiology Group. Public health impact of Rwandan refugee crisis: what happened in Goma, Zaire, in July, 1994? Lancet. 1995; 345(8946):339-44.

6. Okwo-Bele JM, Lobanov A, Biellik RJ, et al. Overview of poliomyelitis in the African region and current regional plan of action. J Infect Dis. 1997; 175(Supplement 1):S10-5.

7. Lambert ML, Doussantousse S, Onadikondo L, Warnet J. Poliomyelitis outbreak in Zaire. Lancet. 1995;346(8973):504-5 ISSN 0140-6736.

8. Hutin YJF, Williams RJ, Malfait $P$, et al. Outbreak of human Monkeypox, Democratic Republic of the Congo, 1996-1997. Emerg Infect Dis. 2001;7(3): 434-8.

9. World health organization: regional Office for Africa: resolution AFR/RC 48/ R2 of 21998. 
10. Organisation Mondiale de la Santé : Office Régional d'Afrique. Guide Technique pour la Surveillance Intégrée de la Maladie et la Riposte dans la Région Africaine, Juillet 2001.

11. Organisation Mondiale de la Santé et CDC. Guide Technique pour la Surveillance Intégrée de la Maladie et la Riposte dans la Région Africaine, 2010.

12. World Health organization. Protocol for evaluation of National Surveillance and response systems concerning communicable diseases, 2002.

13. Guide de la surveillance intégrée des maladies à potentiel épidémique en RD Congo. Février 2003, Ministère de la Santé, pp 13-18.

14. Guide de la surveillance intégrée des maladies à potentiel épidémique en RD Congo. Juin 2012, Ministère de la Santé, pp 17-21.

15. Thacker SB, Stroup DB. Future directions of comprehensive public health surveillance and health information system in United States. Am J Epidemiol. 1994;140(5):383-97.

16. Bompangue D, Giraudoux P, Piarroux M, et al. Cholera epidemics, war and disasters around Goma and Lake Kivu: an eight-year survey. PLoS Negl Trop Dis. 2009;3(5):e436.

17. Bompangue D, Giraudoux P, Plisnier PD, et al. Dynamics of cholera outbreaks in Great Lakes region of Africa, 1978-2008. Emerg Infect Dis. 2011;17:e11.

18. Muyembe JJ, Bompangue D, Mutombo G, et al. Elimination of cholera in the Democratic Republic of the Congo: the new National Policy. J Infect Dis. 2013;208(S1):S86-91.

19. Carine Fenech. Comment analyser les statistiques du système de soins dans les Pays en voie de développement? In: Espace, populations, sociétés, la géographie de la santé en question. 1995; 1:143-147.

20. Fassin D, Cantrelle P, Ferry B. Utilisation des statistiques sanitaires dans les structures périphériques des pays en développement. Bull Soc Path Ex. 1991;84:368-74.

21. Dauphinot V, Naudin F, Gueguen R, Perronnin M, Sermet C. Variation between declared morbidity and diagnosed morbidity. The example of obesity, arterial hypertension and hypercholesterolemy. Issues in Health Economics. 2006;114:1-8.

22. Rowe AK, Kachur SP, Yoon SS, Lynch M, Slutsker L, Steketee RW. Caution is required when using health facility-based data to evaluate the health impact of malaria control efforts in Africa. Malar J. 2009;8:209. https://doi. org/10.1186/1475-2875-8-209.

23. Hoff Nicole Amanda. Utilization assessment of infectious disease surveillance data to enhance methods for better understanding disease occurrence, trends and gaps in disease reporting in a resource limited setting: Monkeypox in the Democratic Republic of Congo, PhD thesis in epidemiology, directed by Anne W. Rimoin, Los Angeles, University of California pp 104, 2014

24. Banque Mondiale (2016) Données par pays. Disponible sur : https:// donnees.banquemondiale.org/pays [consulté le 10 mai 2017].

25. Ministère de la Santé Publique de la République Démocratique du Congo (RDC). Plan national de développement sanitaire 2016-2020 : vers la couverture sanitaire universelle (PNDS 2016-2020). In: Direction i, (editors), Kinshasa: Ministère de la Santé Publique, mars 2016.

26. Liberati A, Altman DG, Tetzlaff J, Mulrow C, Gøtzsche PC, loannidis JP, et al. The PRISMA statement for reporting systematic reviews and meta-analyses of studies that evaluate health care interventions: explanation and elaboration. PLoS Med. 2009;6(7):e1000100.

27. Béguin $M$ et Pumain D. La représentation des données géographiques: statistique et cartographie. Paris: Armand Colin, vol. 192; 1994.

28. Rican S. La cartographie des données épidémiologiques. Les principales méthodes de discrétisation et leur importance dans la représentation cartographique. Cahiers Santé. 1998:8:461-70.

29. Wongsrichanalai C, Mazie JB. Muth ., Sutamihardja a, and Wernsdorfer WH. A review of malaria diagnostic tools: microscopy and rapid diagnostic test (RDT). Am J Trop Med Hyg. 2007;77(6):119-27.

30. Organisation Mondiale de la Santé. Rougeole, 2019. Disponible sur: https:// www.who.int/fr/news-room/fact-sheets/detail/measles (Consulté le 13 mai 2019)

31. Chilundo B, Sundby J, Aanestad M. Analysing the quality of routine malaria data in Mozambique. Malar J. 2004;3:3. https://doi.org/10.1186/1475-2875-3-3.

32. Petersen BW, Rupprecht CE. In: Tkachev S, editor. Non-Flavivirus Encephalitis Human rabies epidemiology and diagnosis. Rijeka, Croatia: InTech; 2011. p. 247-78.

33. Feder HM, Petersen BW, Robertson KL, Rupprecht CE. Rabies: still a uniformly fatal disease? Historical occurrence, epidemiological trends, and paradigm shifts. Curr Infect Dis Rep. 2012;14:408-22. https://doi.org/10.1007/ s11908-012-0268-2.

34. Udow SJ, Marrie RA, Jackson AC. Clinical features of dog and bat-acquired rabies in humans. Clin Infect Dis. 2013;57:689-96. https://doi.org/10.1093/cid/cit372.

35. Shuval JT. The contribution of pyschological and social phenomena to an understanding of the aetiology of disease and illness. Sot. Sci. Med. 1981; 15A: 337-342.

36. Kroeger A. Southamerican Indians between traditional and modern health services in rural Ecuador. Bull Pan Am Health Org. 1982;16:242-54.

37. Kim YK, Sich D, Park TK, Kang DH. Naeng: a Korean folk illness, its ethnography and its epidemiology. Yonsei Med J. 1980;21(2):147-55.

38. Kroeger A. Anthropological and socio-medical health care research in developing countries. Soc Sci Med. 1983;7(3):147-61.

39. Diesfeld HJ, Kuniffo HV, Alihonou E et al. Les soins de santé primaires en république populaire du Bénin. Résultats du projet Bénino-Allemand de Recherche Opérationnelle dans le domaine de la Santé aux Districts ruraux de Banté et de Tori Bossito ; rapport final. Univ. Nationale du Bénin, Fac. des Sciences de la Santé, Dép. de Santé Communautaire, 1988.

40. Houéto D, D'Hoore W, Ouendo EM, Hounsa et Deccache A. Fièvre chez l'enfant en zone d'endémie palustre au bénin : analyse qualitative des facteurs associés au recours aux soins. SFSP | Santé Publique. 2007;19: 363 à 372.

41. Young JC. A model of illness treatment decisions in a Tarascan town. Am Ethnol. 1980;7:106-31. https://doi.org/10.1525/ae.1980.7.1.02a00070.

42. Becker MH, Mainman LA. Models of health-related behavior. In: Handbook of health, health care, and the health professions (ed. D. Mechanic). New York: The Free Press; 1983.

43. Massé R. Culture et santé publique. Les contributions de l'anthropologie à la prévention et à la promotion de la santé. Montréal-Paris : Gaëtan Morin 1995 ; pp 449

44. Penchansky R, Thomas JW. The concept of access. Definition and relationship to consumer satisfaction. Med Care. 1981;19(2):127-40.

45. Manzambi JK, Tellier V, Bertrand F, Albert A, Reginster JY, Balen H. Les déterminants du comportement de recours au centre de santé en milieu urbain africain : résultats d'une enquête de ménage menée à Kinshasa, Congo. Trop Med Int Health. 2000;5(8):563-70.

46. Baxerres $C$, Le Hesran JY. Recours aux soins en cas de fièvre chez l'enfant en pays Sereer au Sénégal entre contrainte économique et perception des maladies. Sciences sociales et santé. 2004:22(4):5-23.

47. Wolffers I. IIIness behaviour in Sri Lanka: results of a survey in two Sinhalese communities. Soc Sci Med. 1988;27(5):545-52.

48. Aday LA, Andersen RM. A framework for the study of access to medical care. Health Serv Res. 1974;9:208-20.

49. Lise O. Gender-health-development. In gender and development. A practical guide. Lise Ostergaard. 1992;7:110-64.

50. Brydon Lynne and Chant Sylvia H. Women in the Third World. Gender Issues in Rural and Urban Areas. 1st ed. New Jersey: Rutgers University Press, New Brunswick; 1989.

51. World Health Organization. Women and health. Better health and welfare systems: women's perspectives, vol. 74. Japan: WHO Kobe Centre International Meeting; 2000.

52. Geissler PW, Harris SA, Prince RJ, et al. Medicinal plants used by Luo mothers and children in Bondo district, Kenya. J Ethnopharmacol. 2002;83(1-2):39-54.

53. Geissler PW, Meinert L, Prince RJ, et al. Self-treatment by Kenyan and Ugandan schoolchildren and the need for school-based education. Health Policy Plan. 2001:16(4):362-71.

54. Haddad S, Nougtara A, Ridde V. Les inégalités d'accès aux services de santé et leurs déterminants au Burkina Faso. Santé, Société et Solidarité. 2004;3(2): 199-210.

55. Ustrup M, Ngira B, Stockman LJ, et al. Potential barriers to healthcare in Malawi for under-five children with cough and fever: a national household survey. J Health Popul Nutr Malar. 2014;32:68-78.

56. Chandra R, Saxena SC, Baue SL, Srivastawa VK, Srivastawa BC. Utilization of services of community health workers by the rural population. Itidicrn J med Rex. 1980:71:975-84.

57. Abasiekong EM. Familism and hospital admission in rural Nigeria-a case study. Sot. Sci. Med. 1981:45-50.

58. Fourn L. Sakou G et Zohoun TH. Utilisation des services de santé par les mères des enfants fébriles au sud du Bénin. Santé publique. 2001;13(2):161-8.

59. Audibert M, Mathonnat J, Henry MC. Social and health determinants of the technical efficiency of cotton farmers in northern Côte d'Ivoire. Soc Sci Med. 2003;56:1705-17. 
60. Geneau R, Lewallen S, Bronsard A and Courtrighf P. The social and family dynamics behind the uptake of cataract surgery: findings from Kilimanjaro region, Tanzania» British Journal of Ophthalmology 2005; 89: 1399-1402.

61. Coulibaly I, Keita B, Kuepie M. Les déterminants du recours thérapeutique au Mali: entre facteurs socioculturels, économiques et d'accessibilité géographique. In: Démographie et Cultures. Actes du colloque de Québec. Association Internationale des Démographes de Langue Française; 2008. p. 223-40.

62. Sanni Yaya, lleka-Priouzeau Samuel. Accès et équité dans les systèmes de soins de santé en Afrique». In Sanni Yaya (eds). Les maux et les choses de la santé. Acteurs, pratiques et systèmes de santé dans le tiers-monde. Québec: Presses de l'Université Laval. 2010; 2: 65-88.

63. Eshetu EB, Woldesenbet SA. Are there particular social determinants of health for the world's poorest countries? Afr Health Sci. 2011;11(1):108-15.

64. Sauerborn R, Ibrango I, Nougtara A, et al. The economic costs of illness for rural households in Burkina Faso. Trop Med Parasitol. 1995;46(1):54-60.

65. Sauerborn R, Nougtara A, Hien M, Diesfeld HJ. Seasonal variations of household costs of illness in Burkina Faso. Soc Sci Med. 1996:43:281-90.

66. Paka E, Hervouët JP. Contribution aux études sur le système de soins modernes en République du Congo : approche géographique. Cahiers Santé. 1998;8:454-60.

67. Daniel G. Le district sanitaire urbain en Afrique subsaharienne. Enjeux, pratiques et politiques. In Karthala - UCL. 2004;448.

68. Maud Harang Cisse. La carte sanitaire à l'épreuve des pratiques sanitaires des citadins : analyse des aires d'attraction des structures de soins à Ouagadougou (Burkina Faso) Territoire en mouvement. [En ligne], 4 | 2007, consulté le 01 novembre 2016. URL: http://journals.openedition.org/tem/ 874.

69. Labosse L. Attractivité des territoires : 14 types de zones d'emploi. In: La France et ses régions. Insee Références; 2010. p. 40-51.

70. Talandier M, Jousseaume V. Les équipements du quotidien en France : un facteur d'attractivité résidentielle et de développement pour les territoires? Norois Environnement, aménagement, société. 2013;226:7-23.

71. Meunier A. L'Etat et l'offre de soins au Burkina Faso. Espace, populations, sociétés. 2000;18(1):33-41.

72. Buschkens WFL, Slikkeveer LJ. Illness behavior of the eastern Oromo in Hararghe. Recommendations for rural health planning in Ethiopia: Institute of Cultural and Social Studies. University of Leiden; 1980.

73. Heggenhougen HK. The utilization of traditional medicine. A Malaysian example Sot Sci Med. 1980;14B:39-44.

74. Sh A. Physical access and utilization of health services in rural Guatemala. Sot Sci Med. 1981;15D:515-24.

75. Fafa Rebouha. Concentration des services de santé, contraintes de mobilité et difficultés d'accès aux soins dans la métropole d'Oran. Territoire en mouvement Revue de géographie et aménagement. [En ligne], 4 | 2007, mis en ligne le 15 décembre 2012, consulté le 13 décembre 2016. URL: http://journals.openedition.org/tem/852.

76. Gérard S. La santé dans la ville. Géographie d'un petit espace dense : Pikine (Sénégal), vol. 350. Paris: Karthala et ORSTOM; 1998.

77. Chapelon L. Politiques de transport et accessibilité : contribution à la conception de réseaux et de services de transport, Habilitation à Diriger les Recherches, Université Paul Valéry-Montpellier 3. 2006 ; 268.

78. Donnat M. Le recours aux soins de santé primaire. L'usage spécifique des lieux, en milieu pastoral au Tchad Inf Géographique. 2009;73:48. https://doi. org/10.3917/lig.734.0048.

79. Salem Gérard, Jeannée Emile. Urbanisation et santé dans le Tiers Monde : transition épidémiologique, changement social et soins de santé primaires. Paris : ORSTOM 1989; 549.

80. Defossez AC, Didier F, Henri G. Espace urbain et santé publique : I'histoire sociale et politique du système de soins à Quito, entre carte et récit. Bulletin de l'Institut Français d. Etudes Andines. 1991;20(1):115-39 ISSN 0303-7495.

81. Fournet $F$ et Salem G. La santé dans les villes africaines, d'idées reçues à la définition d'une urgence de santé publique. Med Trop. 2004;64:567-8.

82. Charreire $H$, Combier E. Équité socio-spatiale d'accès aux soins périnatals en milieu urbain : utilisation des techniques géographiques pour la planification sanitaire. Espace populations sociétés. Espace populations sociétés. 2006;2(3):313-27.

83. Cadot $\mathrm{E}$ et Harang M. Offre de soins et expansion urbaine, conséquences pour l'accès aux soins : I'exemple de Ouagadougou (Burkina Faso)». Espace populations sociétés. [En ligne], 2006/2-3 | 2006, mis en ligne le 31 juillet 2009, consulté le 10 octobre 2016. URL : /index1739.html.
84. Mapatano MA, Piripiri L. Quelques erreurs courantes d'analyse d'un système d'information sanitaire (RD Congo). Santé publique. 2005;17(4):551-8.

85. Arita I, Jezek Z, Khodakevich L, Ruti K. Human Monkeypox: a newly emerged orthopoxvirus zoonosis in the tropical rain forests of Africa. Am J Trop Med Hyg. 1985;34:781-9.

86. O'Leary MJ. Méthode de surveillance active de certaines maladies transmissibles. Pacific Health Dialog. 2000;7(2).

87. Khan AA, Bharadjwaj SM. Access to health care: a conceptual framework and its relevance to health care planning. Evaluation and the Health Professions. 1994;17:60-76.

88. Murray M, Berwick DM. Advanced access. Reducing waiting and delays in primary care. J Am Med Assoc (JAMA). 2003;289(8):1035-40.

89. Bower P, Roland Campbell MJ, Mead N. Setting standards based on patients' views on access and continuity: secondary analysis of data from the general practice assessment survey. Br Med J. 2003;326(7383):258-62.

90. Barlet M, Coldefy M, Collin C and Lucas-Gabrielli V. L'accessibilité potentielle localisée (APL) : une nouvelle mesure de l'accessibilité aux médecins généralistes. Questions d'économie de la Santé. 2012; 174.

91. Berner ES, Graber ML. Overconfidence as a cause of diagnostic error in medicine. Am J Med. 2008;121:S2-S23. https://doi.org/10.1016/j.amjmed. 2008.01.001.

92. Fournier $\mathrm{P}$ et Haddad S. Dimension de la qualité des services de santé en Afrique au Sud du Sahara, in Brunet-Jailly,J (ed), Innover dans les systèmes de santé: Expérience d'Afrique de l'Ouest. Paris, Karthalapp. 1997; 275278,435 .

93. Gerald LB, Tang S, Bruce F, et al. A decision tree for tuberculosis contact investigation. Am J Respir Crit Care Med. 2002;166:1122-7. https://doi.org/ 10.1164/rccm.200202-1240C.

94. Tanner L, Schreiber M, Low JGH, et al. Decision tree algorithms predict the diagnosis and outcome of dengue fever in the early phase of illness. PLoS Negl Trop Dis. 2008;2(3):e196.

95. Meek Jl, Roberts CL, Smith EV Jr, Cartter ML. Underreporting of Lyme disease by Connecticut physicians, 1992. J Public Health Manag Pract. 1996; 2:61-5.

96. Rose CD, Fawcett PT, Gibney KM, Doughty RA. The Overdiagnosis of Lyme disease in children residing in an endemic area. Clin Pediatr (Phila). 1994;33: 663-8. https://doi.org/10.1177/000992289403301105.

97. Orloski KA, Hayes EB, Campbell GL, Dennis DT. Surveillance for Lyme disease - United States, 1992-1998. Morb Mortal Wkly Rep Surveill Summ. 2000;49: $1-11$.

98. Haley VB, Van Antwerpen C, Tserenpuntsag B, et al. Use of administrative data in efficient auditing of hospital-acquired surgical site infections, New York state 2009-2010. Infect Control Hosp Epidemiol. 2012;33:565-71. https://doi.org/10.1086/665710.

99. Jima D, Wondabeku M, Alemu A, et al. Analysis of malaria surveillance data in Ethiopia: what can be learned from the integrated disease surveillance and response system? Malar J. 2012;11:330. https://doi.org/10.1186/14752875-11-330.

100. World Health organization: Recommended strategies for communicable diseases: prevention and control, 2002.

Ready to submit your research? Choose BMC and benefit from:

- fast, convenient online submission

- thorough peer review by experienced researchers in your field

- rapid publication on acceptance

- support for research data, including large and complex data types

- gold Open Access which fosters wider collaboration and increased citations

- maximum visibility for your research: over $100 \mathrm{M}$ website views per year

At BMC, research is always in progress.

Learn more biomedcentral.com/submissions 